\title{
Variants of transcription factor 7-like 2 (TCF 7L2) gene predict conversion to type 2 diabetes in the Finnish Diabetes Prevention Study and are associated with impaired glucose regulation and impaired insulin secretion
}

\author{
J. Wang • J. Kuusisto • M. Vänttinen • T. Kuulasmaa • \\ J. Lindström • J. Tuomilehto • M. Uusitupa • M. Laakso
}

Received: 1 December 2006 / Accepted: 15 February 2007 / Published online: 17 April 2007

(C) Springer-Verlag 2007

\begin{abstract}
Aims/hypothesis We investigated the association of variants of the transcription factor 7-like 2 (TCF7L2) gene with: (1) incident diabetes in the Finnish Diabetes Prevention Study (DPS, Study I); (2) type 2 diabetes and impaired glucose regulation (i.e. IGT or IFG) in a cross-sectional study (Study II); and (3) insulin secretion, insulin sensitivity and adipose tissue expression of TCF7L2 in offspring of type 2 diabetic probands (III).

Subjects and methods Study I (the DPS) included 507 individuals with IGT who were randomly allocated to control and intervention groups and followed for an average
\end{abstract}

J. Wang $\cdot$ J. Kuusisto $\cdot$ M. Vänttinen $\cdot$ T. Kuulasmaa $\cdot$

M. Laakso $(\bowtie)$

Department of Medicine,

University of Kuopio and Kuopio University Hospital,

70210 Kuopio, Finland

e-mail: markku.laakso@kuh.fi

\section{Uusitupa}

Department of Clinical Nutrition,

University of Kuopio and Kuopio University Hospital,

Kuopio, Finland

\section{J. Lindström $\cdot$ J. Tuomilehto}

Department of Epidemiology and Health Promotion,

National Public Health Institute,

Helsinki, Finland

J. Tuomilehto

Department of Public Health, University of Helsinki,

Helsinki, Finland

J. Tuomilehto

South Ostrobothnia Central Hospital,

Seinäjoki, Finland of 3.9 years to monitor for progression to diabetes. Study II was a population-based cross-sectional study of 1,766 men, aged 50-70 years, randomly selected from the population of Kuopio, eastern Finland. Study III included 238 nondiabetic offspring of patients with type 2 diabetes. Genotyping of rs12255372 and rs7903146 of TCF7L2 was carried out.

Results In the DPS, the TT genotype of rs12255372 was significantly associated with an adjusted 2.85 -fold risk (95\% CI 1.17-6.95, $p=0.021)$ of incident diabetes in the control group, but not in the intervention group. In Study II, the adjusted odds ratio in subjects with the TT genotype was $3.40(1.45-7.97, p=0.005)$ for the comparison of diabetic subjects with normoglycaemic subjects. The $\mathrm{T}$ allele of rs 12255372 was significantly associated with decreased insulin secretion (Studies II, III). Expression of TCF7L2 in adipose tissue tended to be lower in subjects with the TT risk genotypes of rs12255372 and rs7903146. Conclusions/interpretation The variant of rs12255372 of TCF7L2 was associated with incident type 2 diabetes in the DPS and in a separate population-based cross-sectional study. Impaired insulin secretion is likely to be the main cause for our findings.

Keywords Genotyping · Impaired fasting glucose · Impaired glucose tolerance - Incidence - Insulin secretion . Insulin sensitivity - Lifestyle intervention - TCF7L2 . Type 2 diabetes - Variants

$\begin{array}{ll}\text { Abbreviations } & \\ \text { DI } & \text { disposition index } \\ \text { DPP } & \text { Diabetes Prevention Program } \\ \text { DPS } & \text { Finnish Diabetes Prevention Study }\end{array}$




$\begin{array}{ll}\text { FPG } & \text { fasting plasma glucose } \\ \text { HOMA-IR } & \begin{array}{l}\text { homeostasis model assessment } \\ \text { for insulin resistance } \\ \text { impaired glucose regulation }\end{array} \\ \text { IGR } & \text { lean body mass } \\ \text { LBM } & \text { 2-h postload glucose } \\ \text { 2-h PG } & \text { single-nucleotide polymorphisms } \\ \text { SNP } & \text { transcription factor 7-like 2 } \\ \text { TCF7L2 } & \text { whole-body glucose uptake }\end{array}$

\section{Introduction}

A study in Icelandic, Danish and US white cohorts recently reported that single-nucleotide polymorphisms (SNPs) of the transcription factor 7-like 2 (TCF7L2) gene, especially rs12255372 and rs7903146, were strongly associated with type 2 diabetes [1]. Subsequently, the Diabetes Prevention Program (DPP) Research Group confirmed that these two SNPs of TCF7L2 predicted progression to diabetes in subjects with IGT [2], while other studies have reported associations of these SNPs with type 2 diabetes in white people and other populations [3-12]. Two of the previous studies have been longitudinal [2,9], and none of them has investigated the functionality of SNPs of TCF7L2 or examined their effects on insulin secretion measured by an IVGTT and insulin sensitivity measured by the euglycaemic clamp in non-diabetic offspring of type 2 diabetic patients.

The present study aimed to investigate the association of rs 12255372 and rs 7903146 of TCF7L2 with incident type 2 diabetes in the Finnish Diabetes Prevention Study (DPS) $[13,14]$ and in a large cross-sectional study including 1,766 men. Furthermore, we investigated the mechanisms how SNPs of TCF $7 L 2$ could increase the risk of type 2 diabetes. We did this by measuring insulin secretion and insulin sensitivity in offspring of type 2 diabetic patients and functionality of the variants of $T C F 7 L 2$ in adipose tissue samples.

\section{Subjects and methods}

Study I: The Finnish Diabetes Prevention Study

The study population has been described earlier in detail $[13,14]$. In short, the DPS is a multicentre study with five participating centres in Finland. The diagnosis of diabetes and other categories of glucose intolerance were based on the criteria of the WHO in 1985 [15]. IGT was defined as fasting plasma glucose (FPG) $<7.8 \mathrm{mmol} / \mathrm{l}$ and a 2 -h plasma glucose in the range of 7.8-11.0 $\mathrm{mmol} / \mathrm{l}$ (OGTT, glucose load $75 \mathrm{~g}$ ). Altogether 522 overweight subjects (BMI 31.1土 $4.6 \mathrm{~kg} / \mathrm{m}^{2}$ ) aged $40-68$ years and with IGT were randomly allocated to one of the two treatment modalities, the intensive diet and exercise intervention group or the control group. The mean duration of follow-up was 3.9 years. DNA for genotyping of rs12255372 and rs7903146 of TCF7L2 was available from 507 subjects (166 men, 341 women).

The intervention programme has been described previously $[13,14]$. Briefly, subjects in the intervention group were given individually tailored dietary advice aimed to reduce weight and the intake of total and saturated fat and to increase the intake of dietary fibre. In addition, subjects in the intervention group were individually guided to increase their level of physical activity. The control group received general information on the benefits of weight reduction, physical activity and healthy diet.

The study protocol was approved by the Ethics Committee of the National Public Health Institute in Helsinki, Finland. All subjects gave written informed consent.

Study II: a population-based cross-sectional study of 1,766 men

An independent study population was collected to confirm the findings of Study I. The primary aim of this study is to investigate the effects of SNPs in genes of interest on the risk of type 2 diabetes and cardiovascular disease in a random sample of Finnish men, aged from 50 to 70 years and living in the town of Kuopio (population 90,000), eastern Finland. A total of 1,766 men from this ongoing population-based study were included. The WHO criteria in 1999 [16] for IGT, IFG and diabetes mellitus were used in the classification of subjects without previously known diabetes, which was based on FPG and 2-h postload glucose (2-h PG) levels in an OGTT conducted at baseline. Among the subjects, 228 had known or newly diagnosed diabetes, 356 had IFG or IGT (impaired glucose regulation [IGR]) and 1,182 had normoglycaemia. The protocol included a 1-day visit to the Clinical Research Unit of the University of Kuopio. Study II was approved by the Ethics Committee of the University of Kuopio and was in accordance with the Helsinki Declaration.

Study III: a study on offspring of type 2 diabetic parents

Study III consisted of 238 non-diabetic offspring of 143 patients with type 2 diabetes (one to four offspring from each family) from our ongoing study [17]. Patients with type 2 diabetes were randomly selected from patients living in the catchment area of Kuopio University Hospital (population 250,000). On day 1, all subjects underwent an 
OGTT to evaluate their glucose tolerance according to the WHO criteria [16]. All subjects had normal liver, kidney and thyroid function, no history of excessive alcohol intake and no severe chronic diseases. Adipose needle biopsy was taken from abdominal subcutaneous tissue for gene expression studies. Informed consent was obtained from all subjects after the purpose and potential risks of the study were explained to them. The protocol was approved by the Ethics Committee of the University of Kuopio and was in accordance with the Helsinki Declaration.

\section{Methods}

Clinical measurements (Studies I-III) Weight and height were measured. BMI was calculated as the weight in kilograms divided by the square of the height in meters.

Oral glucose tolerance test (Studies I-III) During a 2-h OGTT (75 g of glucose) samples for plasma glucose and insulin were drawn at 0 and 120 min in Study I, at 0, 30 and 120 min in Study II and at 0, 30, 60, 90 and $120 \mathrm{~min}$ in Study III to evaluate the degree of glucose tolerance and the insulin response to the oral glucose load. The trapezoidal method was used to calculate glucose AUC and insulin AUC during the OGTT.

Intravenous glucose tolerance test and the euglycaemic clamp (Study III) On day 2, metabolic studies were performed after an overnight fast. First, an IVGTT was performed to determine the first-phase insulin release as previously described $[17,18]$. Immediately after an IVGTT at $60 \mathrm{~min}$, the degree of insulin resistance was evaluated with the euglycaemic clamp technique [19]. After drawing of baseline blood, a priming dose of insulin (Actrapid $100 \mathrm{IU} / \mathrm{ml}$; Novo Nordisk, Gentofte, Denmark) was administered during the initial 10 min to quickly raise the plasma insulin concentration to the desired level, where it was maintained by a continuous insulin infusion of $240 \mathrm{pmol} \cdot \mathrm{kg}^{-1} \cdot \mathrm{min}^{-1}$. Blood glucose was clamped at $5.0 \mathrm{mmol} / \mathrm{l}$ for the next $120 \mathrm{~min}$ by the infusion of $20 \%$ glucose at varying rates according to blood glucose measurements performed at 5-min intervals. The mean rates of glucose infusion during the last $60 \mathrm{~min}$ of the clamp were used to calculate the rates of insulin-stimulated whole-body glucose uptake (WBGU).

Body fat composition (Study II-III) Body composition and lean body mass (LBM) were determined by bioelectrical impedance (RJL Systems, Detroit, MI, USA) in the supine position after a 12 -h fast [20].

Assays and calculation Plasma glucose levels in the fasting state and during the OGTT (Studies I-III) and IVGTT, and blood glucose levels during the euglycaemic clamp (Study III) were measured by the glucose oxidase method (2300 Stat Plus; Yellow Springs Instruments, Yellow Springs, OH, USA). To determine plasma insulin, blood was collected in EDTA-containing tubes. After centrifugation, the plasma was stored at $-70^{\circ} \mathrm{C}$ until analysis. Plasma insulin concentration was determined by a commercial doubleantibody solid-phase RIA (Phadeseph Insulin RIA 100; Pharmacia Diagnostics, Uppsala, Sweden). Insulinogenic index $\left(\Delta \mathrm{I}_{30-0} / \Delta \mathrm{G}_{30-0}\right)$ was calculated as the ratio of the increment of serum insulin $30 \mathrm{~min}$ after an oral glucose load to the increment of blood glucose concentration $30 \mathrm{~min}$ after the glucose load ([30 min insulin-fasting insulin] / [30 min glucose - fasting glucose]) (Studies IIIII) [21]. Insulin AUC during the first 10 min of an IVGTT was calculated according to the trapezoidal rule (Study III). Three measures of insulin sensitivity were used: (1) homeostasis model assessment for insulin resistance $($ HOMA-IR) $($ FPG $[\mathrm{mmol} / \mathrm{l}] \times$ fasting serum insulin [pmol/1]/22.5) [22] (used in Study I); (2) insulin-sensitivity index, which is the reciprocal of fasting insulin concentrations (used in Studies II, III) [23]; and (3) the ratio of WBGU to LBM (WBGU:LBM) based on the euglycaemic clamp (Study III) [24]. Disposition index (DI) was calculated as insulin sensitivity $\times$ first-phase insulin secretion, which is a measure of the beta cell response to insulin sensitivity [25].

Genotyping of the SNPS in TCF7L2 Genotyping of rs12255372 (located in intron 4) and rs7903146 (intron 3) of TCF7L2 was carried out using TaqMan Allelic Discrimination Assays (Applied Biosystems, Foster City, CA, USA). Primers are available upon request from the authors. TaqMan genotyping reaction was amplified on a GeneAmp PCR system 2700 and fluorescence was detected using an ABI Prism 7000 sequence detector (Applied Biosystems). Genotyping success rate was $100 \%$, the error rate in regenotyped SNPs $(7.1 \%$ of all genotypes) was $0 \%$.

Gene expression studies Total RNA from subcutaneous adipose tissue of 86 offspring of type 2 diabetic patients (Study III) was isolated using Trizol reagent (Invitrogen, Carlsbad, CA, USA) and a kit (Qiagen RNeasy Mini; Ambion, Austin, TX, USA), and transcribed to cDNA using random primers and a high-capacity cDNA archive kit (Applied Biosystems). Quantitative RT-PCRs were performed in a 7,500 Real-Time PCR System (Applied Biosystems) using $6 \mathrm{ng}$ (RNA equivalents) of cDNA as template, gene-specific primers and probes (information on primers and probes available upon request from Applied Biosystems). TCF7L2 expression was normalised to large ribosomal protein P0 (Hs99999902_ml, Applied Biosystems) using the standard curve method. 
Statistical analyses Because of the skewed distribution, serum insulin, insulin AUC, the insulinogenic index, HOMA-IR, the insulin-sensitivity index and DI were log transformed for statistical analyses. $\chi^{2}$ test, mixed linear model (adjusted for age, sex, family relationship and WBGU:LBM [Study III]) and univariate ANOVA adjusted for age, sex and BMI were applied to compare differences in characteristics between individuals with different genotypes (Studies I-III). The difference in the frequency of the genotypes by quartiles of the insulinogenic index and tertiles of first-phase insulin release was tested by the $\chi^{2}$ test (linear-by-linear association). In Study I the effect of genotypes on progression to type 2 diabetes was tested with Cox proportional regression models adjusted for confounding factors. Survival curves were calculated to estimate the cumulative incidence of diabetes. The difference in the incidence of diabetes between subjects with different genotypes was tested with the log-rank test. In Studies II and III the effect of each genotype on diabetes or IGR was tested using multiple logistic regression analysis. To assess whether the effect of genotypes differed between the treatment groups (Study I), BMI (Study II), LBM (Study II) and the sexes (Study III), we analysed the first-level interactions between the genotypes of rs12255372 and these parameters. Genetic analyses were done according to the additive model, except where the sample size was small, in which case the dominant model was applied (Study III). All statistical analyses were performed with SPSS 14.0 (SPSS, Chicago, IL, USA).

\section{Results}

The distribution of rs12255372 and rs7903146 followed Hardy-Weinberg expectations in all three Studies. Linkage disequilibrium $\left(r^{2}\right)$ between rs12255372 and rs7903146 was 0.72 in Study I, 0.72 in Study II and 0.68 in Study III.

Table 1 shows characteristics of 507 subjects of the DPS by the genotypes of rs12255372 and rs7903146 in the DPS (Study I). Subjects were middle-aged (age $55.3 \pm 7.1$ years; mean $\pm \mathrm{SD})$, with BMI $\left(31.3 \pm 4.5 \mathrm{~kg} / \mathrm{m}^{2}\right)$ above the normal range. Carriers of the TT genotype of rs $12255372 \mathrm{had}$ higher levels of FPG than carriers of the GG or GT genotypes $(p=0.019)$.

Table 2 shows hazard ratios of the rs12255372 and rs7903146 genotypes for progression to diabetes in the overall cohort $(n=507)$, in the intervention group $(n=259)$ and in the control group $(n=248)$, respectively. There was no significant interaction between these SNPs and the treatment groups (intervention, control) or sexes $(p>0.05)$. Genotypes of rs12255372 and rs793146 were not associated with incident diabetes in the overall cohort or in the intervention group. In the control group, carriers of the TT genotype of rs 12255372 had an adjusted hazard ratio of 2.85 (95\% CI 1.17-6.95, $p=0.021)$ for incident diabetes compared with carriers of the GG genotype. SNP rs7903146 was not significantly associated with the risk of diabetes. Figure 1 (Study I) illustrates the estimated time to the cumulative incidence of diabetes for 248 subjects in the control group, based on the genotypes of rs12255372. Subjects with the TT genotype had a higher cumulative incidence of diabetes than carriers of the GG and GT genotypes (log-rank test, $p=0.009$ ).

Table 3 shows characteristics of 1,538 non-diabetic men (Study II) and 238 non-diabetic offspring of patients with type 2 diabetes (Study III) by rs 12255372 the genotypes. Subjects in Study II were middle-aged men (age 58.5 \pm 5.8 years; mean \pm SD) with BMI of $27.1 \pm 3.8 \mathrm{~kg} / \mathrm{m}^{2}$. Among them, 1,182 had normoglycaemia, 140 had isolated IFG, 142 had isolated IGT, 74 had IFG and IGT, and 228 had type 2 diabetes. Non-diabetic men with the GT and TT genotypes had higher levels of 2-h PG $(p=0.017)$, larger glucose AUCs during the OGTT $(p=0.039)$ and lower DI $(p=0.046)$. Subjects in Study III were middle-aged (age $35.3 \pm 6.4$ years); their BMI was slightly above normal $\left(26.3 \pm 4.8 \mathrm{~kg} / \mathrm{m}^{2}\right)$ and they were non-diabetic on the basis of the OGTT. Among them, 198 had normoglycaemia, five had isolated IFG, 29 had isolated IGT and six had IFG and IGT. Carriers of the GT and TT genotypes were leaner ( $p=$ 0.005) and had decreased insulin AUC during the first $10 \mathrm{~min}$ of the IVGTT compared with carriers of the GG genotype; this applied even after adjustment for insulin sensitivity, measured by the euglycaemic clamp $(p=0.045)$. In rs12255372 and rs7903146 genotypes no statistically significant effects on intra-abdominal fat area (measured by computed tomography, Study III) or fat percentage (Studies II, III) were observed (data not shown).

Table 4 shows odds ratios of the rs 12255372 genotypes for an increased risk of IGR and type 2 diabetes among 1,766 men (Study II). There was no significant interaction between rs12255372 genotypes and BMI or LBM for the risk of type 2 diabetes. The GT and TT genotypes were associated with risk of diabetes compared with non-diabetic subjects. Adjusted odds ratios for subjects with the GT and TT genotypes were 2.11 (95\% CI 1.51-2.94) and 3.40 (1.45-7.97), respectively, for type 2 diabetic subjects versus normoglycaemic subjects.

Figure 2a shows changes in insulin secretion $\left(\Delta \mathrm{I}_{30-0} /\right.$ $\left.\Delta \mathrm{G}_{30-0}\right)$ as changes in insulin sensitivity (1/fasting insulin) among 1,538 non-diabetic male subjects (Study II) according to different genotypes of rs12255272. Carriers of the T allele had decreased insulin release at each level of insulin sensitivity compared with that of subjects with the GG genotype. In addition, the frequency of the $\mathrm{T}$ allele of rs 12255372 non-significantly decreased according to the 
Table 1 Baseline characteristics, by rs12255372 and rs7903146 genotypes, of 507 subjects participating in the Finnish Diabetes Prevention Study (Study I)

\begin{tabular}{|c|c|c|c|c|c|c|c|c|}
\hline & \multicolumn{4}{|c|}{ rs 12255372} & \multicolumn{4}{|l|}{ rs7903146 } \\
\hline & $\begin{array}{l}\text { GG } \\
(n=333)\end{array}$ & $\begin{array}{l}\text { GT } \\
(n=154)\end{array}$ & $\begin{array}{l}\mathrm{TT} \\
(n=20)\end{array}$ & $p$ value $^{\mathrm{a}}$ & $\mathrm{CC}(n=312)$ & $\mathrm{CT}(n=171)$ & $\mathrm{TT}(n=24)$ & $p$ value $^{\mathrm{a}}$ \\
\hline Men/women ${ }^{\mathrm{b}}$ & $113 / 220$ & $47 / 107$ & $6 / 14$ & 0.729 & $104 / 208$ & $56 / 115$ & $6 / 18$ & 0.693 \\
\hline Age (years) & $55.7 \pm 7.1$ & $54.5 \pm 7.0$ & $54.9 \pm 6.3$ & 0.190 & $55.6 \pm 7.2$ & $54.9 \pm 6.9$ & $54.2 \pm 7.1$ & 0.413 \\
\hline BMI $\left(\mathrm{kg} / \mathrm{m}^{2}\right)$ & $31.1 \pm 4.4$ & $31.6 \pm 4.8$ & $30.7 \pm 4.5$ & 0.613 & $31.0 \pm 4.2$ & $31.5 \pm 4.9$ & $32.2 \pm 6.0$ & 0.499 \\
\hline FPG $(\mathrm{mmol} / \mathrm{l})$ & $6.1 \pm 0.7$ & $6.2 \pm 0.8$ & $6.4 \pm 0.8$ & 0.019 & $6.1 \pm 0.8$ & $6.2 \pm 0.8$ & $6.3 \pm 0.7$ & 0.372 \\
\hline 2-h PG (mmol/l) & $8.8 \pm 1.5$ & $8.9 \pm 1.5$ & $9.5 \pm 1.4$ & 0.183 & $8.8 \pm 1.5$ & $8.9 \pm 1.5$ & $9.3 \pm 1.2$ & 0.347 \\
\hline Fasting serum insulin $(\mathrm{pmol} / \mathrm{l})$ & $89 \pm 46$ & $89 \pm 41$ & $82 \pm 41$ & 0.943 & $88 \pm 47$ & $90 \pm 41$ & $87 \pm 41$ & 0.862 \\
\hline 2-h serum insulin $(\mathrm{pmol} / \mathrm{l})$ & $582 \pm 423$ & $558 \pm 331$ & $494 \pm 242$ & 0.795 & $579 \pm 411$ & $560 \pm 368$ & $548 \pm 282$ & 0.844 \\
\hline HOMA-IR & $24 \pm 14$ & $25 \pm 13$ & $24 \pm 14$ & 0.856 & $24 \pm 14$ & $25 \pm 13$ & $25 \pm 14$ & 0.778 \\
\hline
\end{tabular}

Data are expressed as means $\pm \mathrm{SD}$

${ }^{\mathrm{a}}$ ANOVA adjusted for sex, age and BMI except for ${ }^{\mathrm{c}}$

${ }^{\mathrm{b}} \chi^{2}$ test

quartiles of the insulinogenic index $(p=0.076)$ in 1,538 non-diabetic men (Fig. 2b). Figure 2c (Study III) shows that among offspring of probands with type 2 diabetes the frequencies of the $\mathrm{T}$ allele of $\mathrm{rs} 12255372$ significantly decreased according to tertiles of insulin AUC during the first $10 \mathrm{~min}$ of an IVGTT $(p=0.019)$. Similar results were observed for rs7903146 (data not shown).
Finally, we examined TCF7L2 expression in adipose tissue from 86 subjects participating ( 34 men, 52 women; age: $36.9 \pm 6.3$ years; BMI: $\left.26.0 \pm 4.6 \mathrm{~kg} / \mathrm{m}^{2}\right)$ in Study III. Subjects with the GG genotype $(n=61)$ of rs 12255372 had TFC7L2 expression of $1.08 \pm 0.29$ and subjects with the GT $(n=24)$ and TT genotypes $(n=1)$ combined had $0.97 \pm 0.21$, $p=0.09$ (GG vs GT, $p=0.08$ ). Subjects with the $\mathrm{CC}$

Table 2 Hazard ratios of the rs 12255372 and rs7903146 genotypes for incident diabetes $(n=115)$ among 507 subjects with IGT who participated in the Finnish DPS during the 4-year follow-up (Study I)

\begin{tabular}{|c|c|c|c|c|}
\hline & Hazard ratio $(95 \% \mathrm{CI})^{\mathrm{a}}$ & $p$ value & Hazard ratio $(95 \% \mathrm{CI})^{\mathrm{a}}$ & $p$ value \\
\hline rs12255372 & GT & & $\mathrm{TT}$ & \\
\hline \multicolumn{5}{|c|}{ Overall cohort $(n=507)$} \\
\hline Unadjusted model & $1.20(0.81-1.78)$ & 0.370 & $1.80(0.83-3.91)$ & 0.139 \\
\hline Adjusted model $^{\mathrm{b}}$ & $1.17(0.78-1.74)$ & 0.446 & $1.71(0.78-3.73)$ & 0.180 \\
\hline \multicolumn{5}{|c|}{ Intervention group $(n=259)$} \\
\hline Unadjusted model & $1.21(0.65-2.25)$ & 0.556 & $0.54(0.07-3.96)$ & 0.542 \\
\hline Adjusted model & $0.89(0.46-1.70)$ & 0.714 & $0.61(0.08-4.52)$ & 0.624 \\
\hline \multicolumn{5}{|c|}{ Control group $(n=248)$} \\
\hline Unadjusted model & $1.23(0.74-2.06)$ & 0.425 & $3.38(1.43-7.96)$ & 0.005 \\
\hline Adjusted model & $1.27(0.76-2.13)$ & 0.359 & $2.85(1.17-6.95)$ & 0.021 \\
\hline rs7903146 & $\mathrm{CT}$ & & TT & \\
\hline \multicolumn{5}{|c|}{ Overall cohort $(n=507)$} \\
\hline Unadjusted model & $1.29(0.88-1.89)$ & 0.191 & $1.22(0.53-2.81$ & 0.643 \\
\hline Adjusted model $^{\mathrm{b}}$ & $1.29(0.88-1.89)$ & 0.197 & $1.14(0.49-2.63)$ & 0.763 \\
\hline \multicolumn{5}{|c|}{ Intervention group $(n=259)$} \\
\hline Unadjusted model & $1.19(0.65-2.19)$ & 0.577 & $\mathrm{ND}^{\mathrm{c}}$ & $\mathrm{ND}^{\mathrm{c}}$ \\
\hline Adjusted model & $0.98(0.52-1.83)$ & 0.949 & $\mathrm{ND}^{\mathrm{c}}$ & $\mathrm{ND}^{\mathrm{c}}$ \\
\hline \multicolumn{5}{|c|}{ Control group $(n=248)$} \\
\hline Unadjusted model & $1.38(0.84-2.25)$ & 0.202 & $2.10(0.89-4.96)$ & 0.092 \\
\hline Adjusted model & $1.42(0.87-2.33)$ & 0.161 & $1.98(0.83-4.74)$ & 0.125 \\
\hline
\end{tabular}

Genetic analyses done according to the additive model.

${ }^{a}$ The GG genotype was the referent for rs12255372 and the CC genotype for rs7903146; adjusted model: adjusted for age, sex, BMI and FPG.

${ }^{\mathrm{b}}$ Also adjusted for the treatment group (intervention group coded as 1; control group as 2).

${ }^{\mathrm{c}} N D$, not determined due to low number of subjects with the TT genotype (11 subjects). 


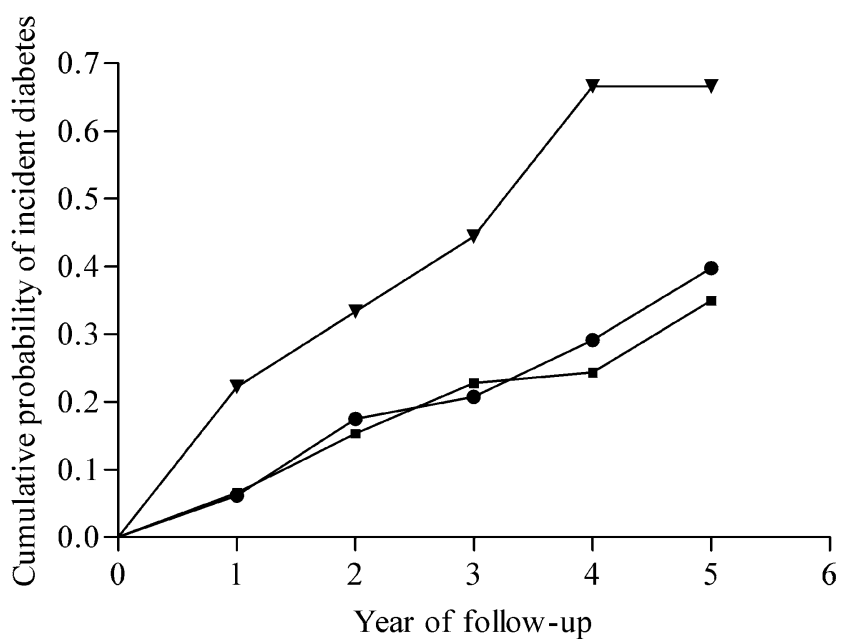

Fig. 1 Cumulative probability of incident diabetes by rs 12255372 genotypes in the control group $(n=248)$ during the 4-year follow-up (log-rank test, $p=0.009$ ) (Study I). Inverted triangles, TT genotype; circles, GT genotype; squares, GG genotype. Total number of subjects at risk: 248, 244, 225, 194, 136, 62 for years 1-5 post follow-up, respectively genotype $(n=57)$, the CT genotype $(n=26)$ and the TT genotype $(n=3)$ of rs7903146 had TCF7L2 expression levels of $1.10 \pm 0.29,0.97 \pm 0.23$ and $0.88 \pm 0.20$, respectively, $(p=0.09)$ (CC vs CT, $p=0.06)$.

\section{Discussion}

We found that the TT genotype of rs12255372 predicted incident diabetes in the control group of the DPS. In a separate large sample of 1,776 men, the TT genotype of rs12255372 was also associated with type 2 diabetes. Furthermore, the T allele of this SNP was associated with decreased first-phase insulin release in an IVGTT in nondiabetic offspring of type 2 diabetic patients. Finally, our study showed that rs12255372 and rs7903146 tended to be associated with altered gene expression of TCF7L2 in adipose tissue samples.

Similarly to the DPP study [2], the DPS also showed that variants of TCF7L2 were associated with incident diabetes in the control group, but not in the intervention group. In the DPP both rs12255373 and rs7903146 predicted progression to diabetes, whereas in the DPS only rs 12255372

Table 3 Characteristics of non-diabetic subjects by the genotypes of rs12255372 (Studies II and III)

\begin{tabular}{|c|c|c|c|c|c|c|}
\hline & \multicolumn{3}{|l|}{ Study II } & \multicolumn{3}{|l|}{ Study III } \\
\hline & GG $(n=1,125)$ & $\mathrm{GT}+\mathrm{TT}(n=413)$ & $p$ value $^{\mathrm{a}}$ & $\mathrm{GG}(n=164)$ & $\mathrm{GT}+\mathrm{TT}(n=74)$ & $p$ value $^{\mathrm{b}}$ \\
\hline Men/women $(n)$ & $1,125 / 0$ & $413 / 0$ & & $76 / 88$ & $36 / 38$ & $0.780^{\mathrm{c}}$ \\
\hline Age (years) & $58.8 \pm 5.8$ & $58.3 \pm 6.0$ & 0.179 & $35.1 \pm 6.4$ & $35.5 \pm 6.2$ & 0.643 \\
\hline BMI $\left(\mathrm{kg} / \mathrm{m}^{2}\right)$ & $27.1 \pm 3.8$ & $27.0 \pm 3.6$ & 0.513 & $26.9 \pm 5.2$ & $25.0 \pm 3.5$ & 0.005 \\
\hline FPG (mmol/1) & $5.5 \pm 0.5$ & $5.5 \pm 0.5$ & 0.706 & $5.2 \pm 0.4$ & $5.2 \pm 0.5$ & 0.605 \\
\hline 2-h PG (mmol/l) & $5.9 \pm 1.6$ & $6.1 \pm 1.7$ & 0.017 & $6.3 \pm 1.5$ & $6.3 \pm 1.3$ & 0.235 \\
\hline Fasting serum insulin (pmol/1) & $50 \pm 37$ & $49 \pm 35$ & 0.835 & $57 \pm 28$ & $49 \pm 20$ & 0.334 \\
\hline 2-h serum insulin $(\mathrm{pmol} / \mathrm{l})$ & $318 \pm 317$ & $336 \pm 317$ & 0.298 & $283 \pm 205$ & $258 \pm 187$ & 0.580 \\
\hline \multicolumn{7}{|l|}{ OGTT } \\
\hline Glucose AUC (mmol $\left.1^{-1} \min ^{-1}\right)$ & $858 \pm 131$ & $874 \pm 140$ & 0.039 & $841 \pm 1,169$ & $832 \pm 144$ & 0.754 \\
\hline Insulin AUC (pmol $\left.{ }^{-1} \min ^{-1}\right)$ & $39,302 \pm 28,608$ & $42,285 \pm 70,501$ & 0.853 & $34,940 \pm 20,192$ & $30,970 \pm 17,865$ & 0.713 \\
\hline Insulinogenic index ${ }^{\mathrm{d}}$ & $101(3,270)$ & $100(12,490)$ & 0.122 & $98(4,146)$ & $77(3,252)$ & 0.689 \\
\hline Insulin-sensitivity index ${ }^{\mathrm{e}}$ & $0.027(0.15)$ & $0.029(0.09)$ & 0.514 & $0.022(0.05)$ & $0.023(0.04)$ & 0.334 \\
\hline \multicolumn{7}{|l|}{ IVGTT, first $10 \mathrm{~min}$} \\
\hline Glucose AUC $\left(\mathrm{mmol} \mathrm{l}^{-1} \mathrm{~min}^{-1}\right)$ & ND & ND & - & $124 \pm 12$ & $121 \pm 11$ & 0.293 \\
\hline Insulin AUC $\left(\mathrm{pmol}^{-1} \min ^{-1}\right)$ & ND & ND & - & $2,980 \pm 1,849$ & $2,230 \pm 1,131$ & 0.045 \\
\hline WBGU:LBM $\left(\mu \mathrm{mol} \mathrm{kg}{ }^{-1} \min ^{-1}\right)$ & ND & ND & - & $54 \pm 18$ & $58 \pm 17$ & 0.155 \\
\hline Disposition index ${ }^{\mathrm{f}}$ & $2.5(165)$ & $2.3(128)$ & 0.046 & $146 \pm 77$ & $126 \pm 63$ & 0.076 \\
\hline
\end{tabular}

Data are expressed as means \pm SD or medians (range).

Data for parameters of IVGTT and WBGU are available for 217 subjects.

$N D$, not determined

${ }^{a}$ ANOVA adjusted for age and body mass index.

${ }^{\mathrm{b}}$ A mixed linear model, adjusted for age, sex, family relationship and WBGU:LBM, was used in all variables except for BMI, WBGU:LBM and DI (adjusted for age, sex and family relationship).

${ }^{\mathrm{c}} \chi^{2}$ test.

${ }^{\mathrm{d}}\left(\Delta \mathrm{I}_{30-0} / \Delta \mathrm{G}_{30-0}\right)([\mathrm{pmol} / \mathrm{l}] \div[\mathrm{mmol} / \mathrm{l}])$

e (1/fasting insulin) (pmol $\left.\mathrm{l}^{-1}\right)$

${ }^{\mathrm{f}}$ Study II: $\Delta \mathrm{I}_{30-0} / \Delta \mathrm{G}_{30-0} \times$ insulin-sensitivity index; Study III: insulin AUC during the first 10 min of an IVGTT $\times$ WBGU:LBM/1000. 
Table 4 Odds ratios of the genotypes of rs 12255372 for IGR (IFG or IGT) $(n=356)$ and type 2 diabetes $(n=228)$ among 1,538 non-diabetic and 228 diabetic men (Study II)

\begin{tabular}{|c|c|c|c|c|c|c|c|c|}
\hline & \multicolumn{8}{|c|}{ Odds ratio $(95 \% \mathrm{CI})$} \\
\hline & \multicolumn{4}{|l|}{ Unadjusted } & \multicolumn{4}{|l|}{ Adjusted $^{\mathrm{a}}$} \\
\hline & GT & $\begin{array}{l}p \\
\text { value }\end{array}$ & TT & $\begin{array}{l}p \\
\text { value }\end{array}$ & GT & $\begin{array}{l}p \\
\text { value }\end{array}$ & TT & $p$ value \\
\hline $\begin{array}{l}\text { IGR vs NGT } \\
(n=1,538)\end{array}$ & $\begin{array}{l}1.39(1.07-1.82) \\
(n=382)\end{array}$ & 0.014 & $\begin{array}{l}1.06(0.45-2.48) \\
(n=31)\end{array}$ & 0.898 & $1.45(1.10-1.90)$ & 0.008 & $1.28(0.53-3.08)$ & 0.577 \\
\hline $\begin{array}{c}\text { DM vs NGT } \\
(n=1,409)\end{array}$ & $\begin{array}{l}2.00(1.48-2.71) \\
(n=360)\end{array}$ & $<0.001$ & $\begin{array}{l}2.74(1.28-5.86) \\
(n=34)\end{array}$ & 0.009 & $2.11(1.51-2.94)$ & $<0.001$ & $3.40(1.45-7.97)$ & 0.005 \\
\hline $\begin{array}{l}\text { DM vs non-DM } \\
(n=1,766)\end{array}$ & $\begin{array}{l}1.84(1.37-2.48) \\
(n=466)\end{array}$ & $<0.001$ & $\begin{array}{l}2.71(1.30-5.64) \\
(n=41)\end{array}$ & 0.008 & $1.96(1.43-2.69)$ & $<0.001$ & $3.10(1.39-6.89)$ & 0.006 \\
\hline $\begin{array}{l}\text { DM vs IGR } \\
(n=584)\end{array}$ & $\begin{array}{l}1.44(1.01-2.05) \\
(n=190)\end{array}$ & 0.046 & $\begin{array}{l}2.59(0.96-6.96) \\
(n=17)\end{array}$ & 0.059 & $1.56(1.08-2.25)$ & 0.019 & $2.51(0.90-7.03)$ & 0.080 \\
\hline
\end{tabular}

Genetic analyses done according to the additive model. The GG genotype was the referent for the comparisons.

$D M$, diabetes mellitus

${ }^{\mathrm{a}}$ Adjusted for age and BMI

was significantly associated with the risk of diabetes. However, this result is consistent with another study in Finns showing that rs 12255372 is more strongly associated with type 2 diabetes than is rs7903146 [4]. Results of the DPP and DPS studies are important for prevention strategies of type 2 diabetes, because they indicate that lifestyle-intervention can efficiently reduce the risk conferred by genetic factors, even when risk genotypes are related to impaired insulin secretion. There are two possible ways of explaining these results. First, lifestyle intervention improves insulin sensitivity as shown in the DPP [23] and DPS [26], making less insulin secretion from beta cells necessary to maintain non-diabetic glucose tolerance. Second, there is a possibility that lifestyle intervention, in addition to improving insulin sensitivity, could also improve insulin secretion capacity.

We also showed that in a cross-sectional study setting (Study II) the T allele of rs12255372 was associated with type 2 diabetes and IGR. This implies that TCF7L2 not only regulates progression to type 2 diabetes, but also increases glucose concentrations at the population level. Therefore, cross-sectional case-control studies that have not evaluated glucose tolerance by an OGTT will probably underestimate the effect of TCF $7 L 2$ on glucose metabolism. On the other hand intervention trials with IGT subjects only (e.g. DPP, DPS) might also underestimate the true effect of TCF7L2 on the risk of diabetes.

Previous studies have suggested that rs12255372 and rs7903146 are associated with decreased insulin secretion $[2,6,9,27]$ or with decreased insulin secretion and insulin resistance [8]. In Study II with a large sample of subjects, we found that in an OGTT the T risk allele of rs 12255372 was associated with glucose AUC and low DI, but not with insulin AUC. In a previous study [6] the T risk allele of rs7903146 was associated with low insulin AUC and low DI in an OGTT. In Study III we applied the euglycaemic clamp technique to measure insulin sensitivity [19] and an IVGTT to estimate first-phase insulin release. We found that the $\mathrm{T}$ risk allele of rs12255372 was associated with low first-phase insulin release (insulin AUC) in an IVGTT, but not with insulin sensitivity. Our results provide further evidence that the variants of TCF7L2 are associated with decreased insulin secretion both in the general population, and in offspring of patients of type 2 diabetes, who have a high risk of developing future diabetes. No association of the variants with insulin resistance could be found in OGTT-derived measures of insulin resistance (Study II) or in clamp-determined insulin sensitivity (Study III).

The mechanisms by which TCF7L2 regulates insulin secretion are not clear. A recent study found that $T C F 7 L 2$ is involved in the activation of mRNA expression of the proglucagon and the glucagon-like peptide- 1 genes in gut endocrine cells [28]. Glucagon-like peptide-1, produced in the gut and brain, lowers blood glucose levels through: (1) stimulation of insulin secretion and biosynthesis; (2) inhibition of glucagon release and gastric emptying; (3) enhancement of peripheral insulin sensitivity; and (4) induction of satiety [29, 30]. Although previous studies $[2,6,9]$ have suggested that the variants of $T C F 7 L 2$ were associated with impaired insulin secretion rather than with insulin resistance, they were based on results from an OGTT or fasting measurement. Our study showed that insulin response to an intravenous glucose bolus was impaired, while that to an oral glucose load was not significantly impaired, suggesting that a deficient 'incretin 
a

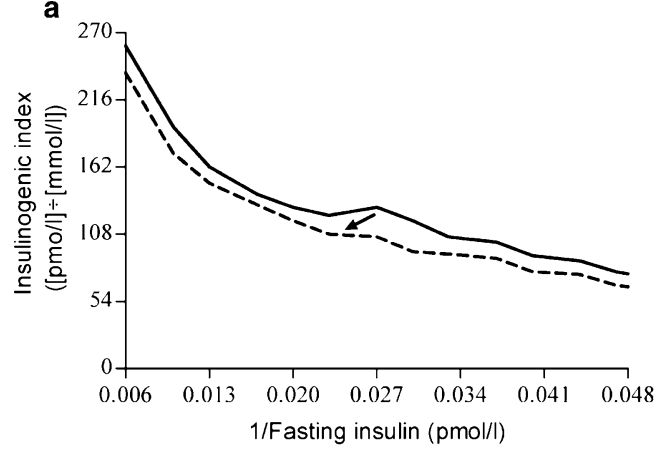

b

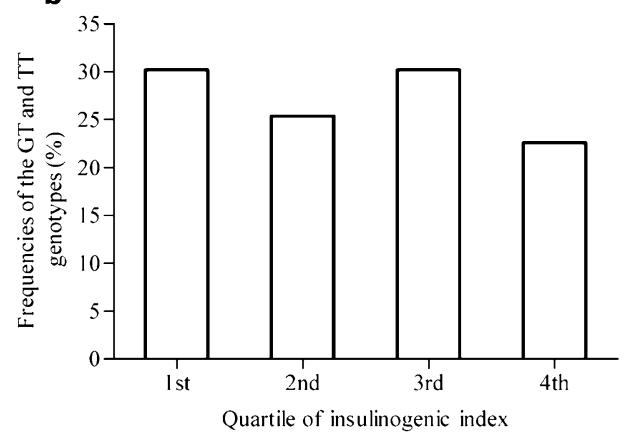

C

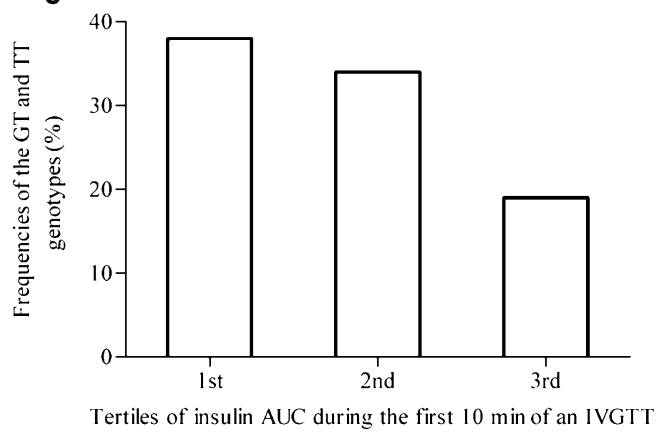

Fig. 2 a Among the 1,538 non-diabetic men in Study II, carriers of the GT and TT genotypes of rs 12255372 had decreased insulin secretion at each level of insulin sensitivity; the curve shifts downwards and to the left (arrow) in those carriers (dashed line). Bold line, GG genotype; dashed line, GT and TT genotypes. b Frequencies of the GT and TT genotypes of s12255372 according to quartiles of the insulinogenic index $\left(\Delta \mathrm{I}_{30-0} / \Delta \mathrm{G}_{30-0}\right)$ in 1,538 nondiabetic men in Study II, $p=0.076$. $\mathbf{c}$ Frequencies of the GT and TT genotypes of s12255372 according to tertiles of insulin AUC during the first $10 \mathrm{~min}$ of an IVGTT in 238 subjects in Study III, $p=0.019$

effect' is unlikely to be the only explanation why rs12255372 is associated with impaired insulin secretion.

A previous study has reported that TCF $7 L 2$ is expressed in human pancreas [7], suggesting direct effects on beta cell development and/or function. Interestingly, in the same study, TCF7L2 expression in human subcutaneous and omental fat tissue was lower in type 2 diabetic subjects than in that of normoglycaemic individuals. These findings were based on only three individuals per group and the results were not confirmed by quantitative PCR [7]. However, in agreement with these results, we showed that the $\mathrm{T}$ risk alleles of rs12255372 and rs 7903146 tended to be associated with low expression of TCF7L2 in subcutaneous tissue

from 86 subjects. Due to a low number of rare homozygous subjects $(n=1-3)$, our results were not statistically significant. These findings need to be further investigated, since TCF7L2 is involved in the regulation of the Wnt signalling pathway [31]. In addition, and similarly to the findings of other studies $[1,2]$, we also found that the $\mathrm{T}$ allele of rs12255372 and rs7903146 was significantly associated with lower BMI in Study III. Therefore, it is possible that Wnt signalling is impaired in adipose tissue of individuals with the risk genotypes of TCF7L2 and may contribute to weight change and hyperglycaemia [32].

A major problem in genetic association studies of complex diseases is inconsistent replication due to limited statistical power as a result of small sample size [33]. This was also the case in our study. In addition, multiple testing increases the likelihood of false positive $p$ values. However, our results are consistent with previous studies on the effects of SNPs of TCF7L2 on the risk of diabetes [1-12, 27]. We therefore believe that our major findings are likely to be true.

In conclusion, our study provides further evidence that common variants of TCF7L2 are associated with type 2 diabetes and IGR. Our study also showed that, in the DPS, it was possible to lower the 'diabetogenic effect' of risk genotypes of rs 12255372 by lifestyle intervention. Impaired insulin secretion attributable to the variants of TCF7L2 is likely to be the main cause of why carriers of the risk genotypes have a high risk of developing type 2 diabetes.

Acknowledgements This work was supported by grants from the Academy of Finland, the European Union (EUGENE2 LSHM-CT2004-512013) and The Kuopio University Hospital (EVO grant no. 5207) to M. Laakso.

Duality of interest None of the authors had any conflicting interests in connection with this study.

\section{References}

1. Grant SF, Thorleifsson G, Reynisdottir I et al (2006) Variant of transcription factor 7-like 2 (TCF7L2) gene confers risk of type 2 diabetes. Nat Genet 38:320-323

2. Florez JC, Jablonski KA, Bayley N et al (2006) TCF7L2 polymorphisms and progression to diabetes in the Diabetes Prevention Program. N Engl J Med 355:241-250

3. Groves CJ, Zeggini E, Minton J et al (2006) Association analysis of 6,736 U.K. subjects provides replication and confirms TCF7L2 as a type 2 diabetes susceptibility gene with a substantial effect on individual risk. Diabetes 55:2640-2644

4. Scott LJ, Bonnycastle LL, Willer CJ et al (2006) Association of transcription factor 7-like 2 (TCF7L2) variants with type 2 diabetes in a Finnish sample. Diabetes 55:2649-2653

5. Zhang C, Qi L, Hunter DJ et al (2006) Variant of transcription factor 7-like 2 (TCF7L2) gene and the risk of type 2 diabetes in large cohorts of U.S. women and men. Diabetes 55:2645-2648

6. Saxena R, Gianniny L, Burtt NP et al (2006) Common single nucleotide polymorphisms in TCF7L2 are reproducibly associated 
with type 2 diabetes and reduce the insulin response to glucose in nondiabetic individuals. Diabetes 55:2890-2895

7. Cauchi S, Meyre D, Dina C et al (2006) Transcription factor TCF7L2 genetic study in the French population: expression in human beta-cells and adipose tissue and strong association with type 2 diabetes. Diabetes 55:2903-2908

8. Damcott CM, Pollin TI, Reinhart LJ et al (2006) Polymorphisms in the transcription factor 7-like 2 (TCF7L2) gene are associated with type 2 diabetes in the Amish: replication and evidence for a role in both insulin secretion and insulin resistance. Diabetes 55:2654-2659

9. Cauchi S, Meyre D, Choquet H et al (2006) TCF7L2 variation predicts hyperglycemia incidence in a French general population: the data from an epidemiological study on the Insulin Resistance Syndrome (DESIR) study. Diabetes 55:3189-3192

10. van Vliet-Ostaptchoul JV, Shiri-Sverdlov R, Zhernakova A et al (2007) Association of variants of transcription factor 7-like 2 (TCF7L2) with susceptibility to type 2 diabetes in the Dutch Breda cohort. Diabetologia 50:59-62

11. Humphries SE, Gable D, Cooper JA et al (2006) Common variants in the TCF7L2 gene and predisposition to type 2 diabetes in UK European Whites, Indian Asians and Afro-Caribbean men and women. J Mol Med 84:1-10

12. Chandak GR, Janipalli CS, Bhaskar S et al (2007) Common variants in the TCF7L2 gene are strongly associated with type 2 diabetes mellitus in the Indian population. Diabetologia 50:63-67

13. Eriksson J, Lindstrom J, Valle T et al (1999) Prevention of Type II diabetes in subjects with impaired glucose tolerance: the Diabetes Prevention Study (DPS) in Finland. Study design and 1-year interim report on the feasibility of the lifestyle intervention programme. Diabetologia 42:793-801

14. Tuomilehto J, Lindstrom J, Eriksson JG et al (2001) Prevention of type 2 diabetes mellitus by changes in lifestyle among subjects with impaired glucose tolerance. N Engl J Med 344:1343-1350

15. World Health Organization (1985) Diabetes mellitus: report of a WHO Study Group. Technical Report Series, no. 727. WHO, Geneva

16. World Health Organization (1999) Definition, diagnosis and classification of diabetes mellitus and its complications. Report of a WHO consultation. Part 1: Diagnosis and classification of diabetes mellitus. Publication no. WHO/NCD/NCS/99.2, WHO, Geneva. http://whqlibdoc.who.int/hq/1999/who_ncd_ncs_99.2.pdf

17. Salmenniemi U, Ruotsalainen E, Pihlajamaki J et al (2004) Multiple abnormalities in glucose and energy metabolism and coordinated changes in levels of adiponectin, cytokines, and adhesion molecules in subjects with metabolic syndrome. Circulation 110:3842-3848

18. Galvin P, Ward G, Walters J et al (1992) A simple method for quantitation of insulin sensitivity and insulin release from an intravenous glucose tolerance test. Diabet Med 9:921-928
19. DeFronzo RA, Tobin JD, Andres R (1979) Glucose clamp technique: a method for quantifying insulin secretion and resistance. Am J Physiol 237:E214-E223

20. Fuller NJ, Elia M (1989) Potential use of bioelectrical impedance of the 'whole body' and of body segments for the assessment of body composition: comparison with densitometry and anthropometry. Eur J Clin Nutr 43:779-791

21. Phillips DI, Clark PM, Hales CN et al (1994) Understanding oral glucose tolerance: comparison of glucose or insulin measurements during the oral glucose tolerance test with specific measurements of insulin resistance and insulin secretion. Diabet Med 11:286292

22. Matthews DR, Hosker JP, Rudenski AS et al (1985) Homeostasis model assessment: insulin resistance and beta-cell function from fasting plasma glucose and insulin concentrations in man. Diabetologia 28:412-419

23. Kitabchi AE, Temprosa M, Knowler WC et al (2005) Role of insulin secretion and sensitivity in the evolution of type 2 diabetes in the diabetes prevention program: effects of lifestyle intervention and metformin. Diabetes 54:2404-2414

24. Vauhkonen I, Niskanen L, Vanninen E et al (1998) Defects in insulin secretion and insulin action in non-insulin-dependent diabetes mellitus are inherited. Metabolic studies on offspring of diabetic probands. J Clin Invest 101:86-96

25. Kahn SE, Prigeon RL, McCulloch DK et al (1993) Quantification of the relationship between insulin sensitivity and beta-cell function in human subjects. Evidence for a hyperbolic function. Diabetes 42:1663-1672

26. Uusitupa M, Lindi V, Louheranta A et al (2003) Long-term improvement in insulin sensitivity by changing lifestyles of people with impaired glucose tolerance. 4-year results from the Finnish Diabetes Prevention Study. Diabetes 52:2532-2538

27. Munoz J, Lok KH, Gower BA et al (2006) Polymorphism in the transcription factor 7-like 2 (TCF7L2) gene is associated with reduced insulin secretion in nondiabetic women. Diabetes 55:3630-3634

28. Yi F, Brubaker PL, Jin T (2005) TCF-4 mediates cell typespecific regulation of proglucagon gene expression by betacatenin and glycogen synthase kinase-3beta. J Biol Chem 280: $1457-1464$

29. Kieffer TJ, Habener JF (1999) The glucagon-like peptides. Endocr Rev 20:876-913

30. Turton MD, O'Shea D, Gunn I et al (1996) A role for glucagon-like peptide- 1 in the central regulation of feeding. Nature 379:69-72

31. Ross SE, Hemati N, Longo KA et al (2000) Inhibition of adipogenesis by Wnt signaling. Science 289:950-953

32. Smith U (2007) TCF7L2 and type 2 diabetes - we WNT to know. Diabetologia 50:5-7

33. McCarthy MI, Groop PH, Hansen T (2005) Making the right associations. Diabetologia 48:1241-1243 